\title{
Playing your network: gaming in social network sites
}

\author{
Luca Rossi \\ University of Urbino "Carlo Bo" \\ LaRiCA - Via Saffi, 15 - 61029 Urbino - Italy \\ Luca.rossi@uniurb.it \\ +390722305726
}

\begin{abstract}
Recently the use of social network sites have emerged as one of the most important and time-consuming online activities. In the large and diversified social network scenario Facebook emerged as one of the most important sites at least in the United States and in Europe. In the Facebook-based gaming scene Playfish, a UK based company, has recently gained a leading position with more than 50 million registered players. The paper will analyze these five games, observing, starting from Playfish's games, how Facebook games use the social network site and the social relationships between players as a core element for the game experience. In SNS several different contexts of life seems to exist one near the others and eventually overlapping. Closest friends with co-workers, relatives with ex-schoolmates: the paper will present how the new SNS environment can be used for gaming and how gaming activities change when they enter the collapsed context of SNSs.
\end{abstract}

Author Keywords:

SOCIAL NATWORKS, SOCIAL GAMES, SOCIAL CAPITALS, ONLINE GAMING

\section{GAMING IN SOCIAL NETWORK SITES}

Social networks sites seem to be a growing phenomenon over the Internet. Services such has Friendster, Myspace and now Facebook saw growing rates never registered before and, despite the absence of a single global leader [3], this kind of services are facing all over the world an unquestionable success. This paper will describe how games evolved as a specific part of the Social Network Sites services and it will propose an analysis of how gaming change in SNS digital environment.

The phenomenon of online social networking seems global while the Social Network Sites (SNSs) that are used seems to be strictly related to a series of cultural and local issues. According to a recent survey while Facebook is the big player in almost every western country (with more than 200 millions of users), Asia, Russia and South America show a very different scenario with completely different platforms [3]. On a global scale QQ, which is the SNS most used in China, counts more than 300 millions of users. Nevertheless this paper will focus on Facebook as the leading SNSs in most western countries. This is leading the author to a double premise: on one side the Facebook users base is large enough for a study about gaming practices; on the other side, since most of the observed practices are strictly connected to the technical reality of the SNSs itself generalization shouldn't be done before any comparative analysis.

If we go through Facebook looking for gaming activities we might be surprised by how evident and wide spread they are. Gaming seems to be everywhere in SNSs even in the absence of proper gaming applications. Previous analyses have suggested that the SNSs structure itself can be used in order to play relational games with friends or other users [6]. Nevertheless this paper will not observe the game "hidden inside" Facebook, but it will focus on the many games that are clearly defined as such. Gaming applications are not, in fact, part of the SNSs but came as external applications that can be added (installed) to your profile. Due to the Facebook architecture every action that you perform within the system is, o might be, public. Then even installing a game, that's the first required step in order to play a game, will give you the opportunity to publish on your profile (and to notify all your friends) the fact that you are adding a specific game. This is a first step that makes the gaming activities "go public". The fact that someone is playing, or rather has just installed, Vampires rather than Biggest brain (just to reports few of the Facebook games names we're analyzing later) became a news shared between a list of contacts that Facebook calls friends. The friends ${ }^{l}$, list that Facebook provides isn't necessarily related to the offline peer group that is usually defined with the same word but it keeps together a wide range or relationships: from the co-workers to the former schoolmates, from the people you've met once during a conference to some real friends.

"[...] who you connect to on Facebook or MySpace or Twitter is not the same list of people that you would say constitute your closest and dearest. The practice of publicly

\footnotetext{
${ }^{1}$ The form friend(s) will be used to refer to an other Facebook users sho is connected the the user's profile with a friendship link. The form friend(s) will be used to identify the closest peer group.
}

\section{Breaking New Ground: Innovation in Games, Play, Practice and Theory. Proceedings of DiGRA 2009}


articulating one's social network can be quite fraught because there are social costs to the process of public articulation. Issues of reciprocity emerge and people find themselves doing a lot of face-work to navigate the sticky nature of having to account for their social relations in a publicly accountable way." [2]

Even if recently Facebook provided a much more granular management of privacy settings: allowing the user to collect friends in lists and to assign to each list a specific access level to user's information, the standard settings suppose you to share your information within (Facebook) friends.

If gaming in Facebook is a semi-public activity it is interesting to observe how most of the games that were, and largely still are, very popular on the platform make an extensive use of this characteristic. Games like Vampires, Zombies, Werewolves, Slayers (that are actually made by the same company and could be considered four parts of a single game) or Jedi vs Siths, even if now show a complex game design based on collecting objects, accomplishing quests and fighting with others players, had, at the beginning, a very simple structure. Those games were basically based on the asynchronous fight between players. The players was basically allowed to fight all his/her friends that were playing the same game and more friends he/she was able to bring into the game more bonuses he/she had and more powerful he/she was. There wasn't any real challenge; no special abilities were required. Being able to bring as many friends as possible into the game (making them installing the game application) was the key to became a great Vampire/Werewolf/Zombie/Slayers or Jedi. The achievement is shown on a game ladder that displays the results of all your Facebook friends playing. In this first kind of Facebook games the challenge offered by the game is really low and most of the fun seems to come from the social interactions that exists behind the game. To be the most powerful vampire in the global ladder can surely be an achievement for few but to desire to be the first on the local ladder made by the player and his/her Facebook friends is quite a common experience. Nevertheless to that goal is not based on any particular skill or knowledge, due to the game structure it is only matter of lucky time and friends. The use of SNSs to negotiate personal social status is a widely recognized practice [1] and the games ladders seems to offer a gaming opportunity to do that. After this first generation of games the gaming scene in Facebook faced an rapid evolution bringing into the SNS environment some real challenge and complex game's dynamics. This second generation of Facebook gaming has see many actors but one of the most important is surely the UK based company Playfish. With 7 published Social games (Playfish is developing its games mainly for Facebook but some of them can also be played in different SNS such as MySpace or Bebo) and more than 11 million players per month Playfish is the largest company of this market; at least 5 out of 7 currently available games are still ranked in the top 25 gaming apps for Facebook and Pet Society, which is probably the biggest hit of the company, recently was the first Facebook application to reach 1 million of fan within the SNS itself. On the company's website it is possible to read an interesting description about how Playfish perceive itself and about how the company understands the difference between SNSs based computer games and traditional computer games:

"Social games are games designed to be played together with friends.

Traditional computer games focus on standalone game play on consoles, your PC or on your mobile. Games that do allow you to play together with others online normally require you to buy the game, go online and try and find like-minded new friends who are also playing the game. This is something that usually only the most dedicated gamers are prepared to do.

Our social games are different. We create games that let you play together with real-world friends and family using the infrastructure built by social networks. This is in some ways a return to the roots of games. You play with the same people you would play cards, board games or go bowling with in the real world. Sharing the game experience with friends makes it more compelling and fun."

The most interesting part, but we are going to come back to this definition later in the paper, is the clear perception of gaming as an activity that acquire higher value when it is played together with someone you already know. Playfish focuses on games that grows up from the relationship and not on games that are the shared passion of players. SNSs games, it is stated, moves back to the roots of the gaming experience when gaming activities where shared with reallife friends. Despite the claims of Playfish every game scholar is well aware that the relationship between gaming practices and friendships is complex and blurry. If it is undoubtedly true that games can be the center of community of practices that starts from a common interest in the game [7] it has been observed how often the gaming experience is shared with relatives or real-life friends [8]. Sometimes the game seems to be just another place where experience frienship which pre-exist the gaming practice. Players not only make friends in games but also, play games with friends. Gaming activities are, within this perspective, a place where friendship can take place, where social status and relationships can be negotiated. Recent researches have pointed out that hanging out gaming [5] is a wide spread practice among teenagers. This kind of practice can be observed both in computer/console based digital games, where teenagers gather together to play the same game or just to watch each other playing, and in online MMOs where teens seem to log-in just to hang out in the virtual environment with their friends:

"Hanging out gaming also includes online practices such as participating in social guilds in massively multiplayer online games (MMOGs), where players enjoy the social affordances constructed by the games. MMOG players 
spend many hours logged into the shared space of the game, and much of that time is occupied with casual hanging out, conversation, and activities such as bartering or exploring. The time spent actively pursuing game goals is only one part of what they do online. The time and space around the more goal-directed activities of gaming becomes a site for social conversation and sharing. " [5]

To spend some time together no matter if that time is hardly aimed to achieve something or not. The point is the social relationship existing behind the game. But moving this definition in SNS requires new investigations due to the uniqueness of the digital connected environment. SNSs on a wider perspective, and Facebook as long as it concerns this paper ambitions, are the space where contexts collides where the lack of spatial, social and temporal boundaries makes it difficoult to maintain distinct social context (boyd 2008). Facebook is the place where friends are somehow different than Friends and where this difference provides a brand new gaming space. Within this perspective Playfish's claims are both true and false at the same time. They are true because the social relationship preexists the gaming experience making it even more fun and engaging; they are false because in Facebook friends defines a wide, and often blurry, range of different social relationships from your real mates to your colleagues, bosses, neighbors, students and much more. Is it really possible to hang out gaming in this context? By describing Playfish's games and by dividing them into two major categories this paper will point out few elements that can be useful to answer these questions.

\section{BETWEEN PETS AND (BIGGEST) BRAINS}

Playfish published a wide range of different games: according to their website ${ }^{2}$ eight titles are currently available (Crazy planets, Restaurant City, Minigolf Party, Pet Society, Geo Challenge, Word Challenge, Bowling Buddies and Who Has The Biggest Brain?) and another one (Country Story) is going to be released soon. These games, even if represent a large variety of different scenarios, can be grouped in three groups according to their game design. Minigolf party and Bowling Buddies are basically simple skill based games with very simple and easy to learn game dynamics; Who has The Biggest Brain?, Geo Challenge and Word Challenge are knowledge based games that ask the player to solve a specific problem (answer geography questions, solve logic problems or compose words from scrambled letters) in a given amount of time; while Pet Society and Restaurant City are managerial/pet games where the player have to take care of a restaurant or of a pet in a gaming world populated by your friend's pets or restaurants. Crazy planets is not listed since it has been released recently and has not being taken into consideration for this study. If we want to move on grouping Playfish's

\footnotetext{
${ }^{2}$ http://www.playfish.com
}

games they can be grouped further in two main categories: skill/knowledge games and truly social games. Obviously every Playfish's game is a social game but nevertheless it seems possible to make a distinction between those games that offer an inner challenge (and where the social relationship start from the results of the game itself) and those that seem to be pointless if played alone. Using this rather strict categorization then it is possible to label Minigolf party, Bowling Buddies, Who has The Biggest Brain?, Geo Challenge and Word Challenge as skill/knowledge games while Pet Society and Restaurant City as more proper social games. This distinction becomes more useful since it links a specific characteristic of the game itself to the specific relationship that players set up with SNS friends using the game. In skill/knowledge games player is asked to perform specific tasks or to answer specific questions. The player will score a specific amount of points and he will be placed on a ladder that has three main option "friends", "country" and "global". The global and the country ladders show scores from player according to a geographical factor (nation-wide or global) giving the player the opportunity to understand how good he/she is on a larger level. The friends ladder shows only the friends playing game and gives to the player the opportunity to compare himself/herself result with his/her inner circle. This ladder system represent a double social usage of the game: on one hand the player can compare him/herself with a larger (and mostly unknown) group of players to see who is the best "in the world" or "of the country" and, on the other hand the player has the opportunity to use the gaming performance in order to stress his/her social status within the friends group. A Geo Challenge player that has been interviewed during some preliminary researches claimed " $I$ don't really like the game, it is boring after a while, I play it only to be the first [in his friends ladder]... now I'm not playing it but if someone should beat my score then I'm going to play it again. Just the be back on top". Here the performance obtained by the gaming activity is used to state and stress something about the relationship or about the identity that the player try to negotiate within the SNS. The use of the gaming result to add something to your profile is well understood by Playfish that offer to players the opportunity to publish on their profile every record they score; to challenge a specific friend in a one-on-one competition or even to brag about their performance on others' profiles.

What's different with those games that we've defined as purely social? If the observe how Pet Society and Restaurant City work we can find the same double ladder system to compare your achievements with those of all the players or of your friend playing the game. At the same time the challenge is not the core element of the game and it is replaced by the continuous attention required by pet and managerial games. It is of course possible to describe those games in terms of scores but the core activity for players is not to reach the highest score but to take care of their pets or restaurant in order to obtain a most fancy house or 
restaurant according to their her own tastes and desires. Those games requires a different kind of playing style; instead of trying to play them again and again in order to improve the scores players are asked to play in a light continuous way just to do many little things: clean up your restaurant, dress your pet, visit a friend's pet, etc. These activities don't require a large amount of time and can be accomplished even with a very low level of attention toward the game (on the other side skill/knowledge games are often time-based and require the complete attention of the player). A player stated "I log in at least once every day.. just the time to take the money from the lottery and, if I've got time, to go and visit all the Pets I know". There is no competition between players and the game interact with you social network in a completely different way. In Pet Society you gain some money every time you go and visit a friend, in a similar way, in Restaurant City player gains ingredients (that are required to prepare recipes ) every time he goes and visit a friend's restaurant or ingredients can even be traded between friends ${ }^{3}$. Both in Pet Society and in Restaurant City the friends network is not used as a background for players' performance, friends are not opponents but they are a resource that have to be used to move further with the game. To play the game you have to use your network and, if it is possible, even to enlarge it. Many players reported that they forced people to start playing the game: "I've pushed some into the game.. now they like it a lot". Most interesting is that due to the fact that every playing friend is, de facto, a resource within the game players started adding each other as Facebook friends just to be able to get one more pet or restaurant to visit into the game. "I've added many friends because of the game... but I usually handle them on a separate friend group"; "Of course I did! [adding Facebook friends because of the game]... they are in a dedicated list". The most notable aspect is not the fact that players act in a strategic way and, once they realize games dynamics, starting adding players as friends; is the fact that those friends are labeled and managed in a different category. They seems to be more useful contacts than friends even if the SNS labels them that way.

\section{BOUNDARIES AND (BROKEN) BRIDGES}

SNSs have often been observed and described in terms of the ability that they have to strengthen existing social relationships or easily increase the number of those [4] . Differences between bounding practices, that are the practices aimed at strengthening existing relationships, and bridging practices, those practices aimed at expanding the network, have been identified both in technical aspects

\footnotetext{
${ }^{3}$ Both these games include a micro-payment system that allows players to purchase things for little amount of money speeding up, in that way, the achievement of goals within the game.
}

(some SNS is more indicated for bounding practices than others) and in cultural aspect [4]. Bridging and bounding activities have been described also within MMOs and there are a number of researches that support the idea of MMOs as potential third places able to improve socialization processes and to enlarge social network [8]. The merging of SNSs technologies and gaming activities give us the opportunity to re-think these categories and to observe how the observed Facebook games work from the point of view of social networking. As described knowledge/skill based games seems to be mostly played in an already existing network and are sometimes used to stress (or redefine) existing relationships. Even is further research is surely needed this seems to happen even in a collapsed context where the group is wider and not so well defined as it often is offline. This happens when the social network is, within the game's dynamics, a collection of potential opponents, people to challenge and, possibly, to defeat. There the game seems to be more often played within the already existing network and challenge is not often a reason to enlarge the network by adding new friends. This seems to lead toward the use of the gaming practices as bounding practices.

Looking at what we called truly social games we see a completely different scenario. The need to use other players as a part of the gaming strategy pushes players into adding friends just for the game. Since there is not real competition between players this is a win-win situation where both have mutual benefits from the connection. This specific outcome could suggest truly social games as bridging games able to give to players the opportunity to enlarge their own network. However the new connections, the new nodes on the network, that came from this kind of gaming activity don't seem to be perceived as a true growth of the social connectivity. What seem to happen is a rather strategic use of these new connections: as long as they are useful for the game. So there is no real expansion of the network not from the size or for the social capital. These links seem to be even weaker that then weak ties that usually constitute the SNSs based networks.

\section{CONCLUSIONS}

Aim of this paper was to present some preliminary reflections of how SNSs, as an environment for games, change gaming practices and offer new and unexplored direction both to game designers and to SNSs. The described Playfish's games have been categorized, according to how the game deals with the network of friends, in two groups: skills/knowledge based and truly social games. Skills/knowledge based games (like geochallenge or Who Has The Biggest Brain?) seem to use the actual network of people linked to the player as a list of potential challengers. This seems to lead toward the use of the game within the already existing group with group related purposes: challenging each other, be the on top of all 
your friends etc. etc. This kind of gaming practice seems to be more interested in the relationship than in the game itself. It is not unusual, in fact, to move from a skills/knowledge based game to another one as soon as the group, or part of the group, get bored with it.

Truly social games, on the other hand, use the player's network as a resource for the game itself. Games like Pet Society or Restaurant City don't offer a real challenge to the player but they give him/her the opportunity to "take care" of something (no matter if this is a sweet colorful pet or a restaurant). In order to achieve their goal players need to use their network by visiting friend's pet or restaurants to obtain money or ingredients. The social network here is an important strategic resource. For this reasons players seem more likely to add strangers to their friends list but this new node of the network can't be really describe as an enlargement of the network (a bridging activity) because these nodes seems to be managed in different way than the real network is.

Obviously this is just a preliminary reflection based on few observation and interviews but it suggest many interesting aspects for game and SNS research. On one side gaming practices seem to be very popular between SNSs users and SNS environment offers a new challenge and many opportunities to game designers and scholar. On the other side it seems possible to underline how gaming in SNS have to be studied as a specific branch of online gaming since what happens in these environments it is not really comparable to MMOs or any other online gaming environment.

\section{REFERENCES}

1. boyd, D. Taken Out of Context: American Teen Sociality in Networked Publics. PhD Dissertation. University of California-Berkeley, School of Information 2008.

2. boyd, D. Would the real social network please stand up? apophenia, July, 28th 2009. http:/www.zephoria.org/thoughts/archives/2009/07/28/ would_the_real.html.

3. Cosenza, V. World Map of Social Networks. Vincos Blog, 2009. http://www.vincos.it/world-map-of-socialnetworks/.

4. Giglietto, F. The Italian way to SNSs - a comparison between Badoo and Facebook. paper presented at IR9 Conference - ITU University, Copenhagen, 2008.

5. Ito, M., Horst, H.A., Bittanti, M., boyd, D., HerrStephenson, B., e Lange, P. White Paper - Living and Learning with New Media: Summary of Findings from the Digital Youth Project. MacArthur Foundation Reports on Digital Media and Learning, 2008.

6. Mortensen, T.E. Flickr, the MMORPG, papaer presentet at Academic Barcamp, University of Urbino, 2008.

7. Taylor, T.L. Play Between Worlds: Exploring Online Game Culture. The MIT Press, 2006.

8. Williams, D., Ducheneaut, N., Xiong, L., Zhang, Y., Yee, N., e Nickell, E. From Tree House to Barracks: The Social Life of Guilds in World of Warcraft. Games and Culture 1, 4 (2006), 338-361. 